Article

\title{
Thermodynamic Assessment of the Suitability of the Limiting Selectivity to Screen Ionic Liquid Entrainers for Homogeneous Extractive Distillation Processes
}

\author{
Andrew S. Paluch * (D) and Pratik Dhakal \\ Department of Chemical, Paper and Biomedical Engineering, Miami University, Oxford, OH 45056, USA; \\ dhakalp@miamioh.edu \\ * Correspondence: paluchas@miamioh.edu; Tel.: +1-(513)-529-0784
}

Received: 2 October 2018; Accepted: 6 November 2018; Published: 9 November 2018

\begin{abstract}
As a result of their high tuneability and low volatility, room temperature ionic liquids have been proposed as replacement solvents in a wide range of industrial applications. They are particularly well-suited for use as an entrainer (or solvent) in extractive distillation processes to separate close boiling and azeotropic mixtures. The limiting selectivity is a common, fundamental parameter used to screen and rank entrainer candidates. In the present study, we present a detailed thermodynamic analysis to understand the basis for its use along with the necessary, underlying assumptions. We find that, while for many cases the limiting selectivity can correctly rank ionic liquid entrainer candidates for homogeneous extractive distillation processes, it is not always able to capture the correct phase behavior. We, instead, recommend the use of composition dependent activity coefficients.
\end{abstract}

Keywords: phase equilibrium; extractive distillation; entrainer; azeotrope; ionic liquid; limiting activity coefficient

\section{Introduction}

The separation of azeotropic and close boiling mixtures via distillation is not without great challenges. If we consider the Fenske equation for a distillation column at total reflux, for a binary mixture, the minimum number of equilibrium stages required is inversely proportional to the log average relative volatility [1]. We find that the smaller the value of the relative volatility, the greater the number of required stages, and in the limit that the relative volatility goes to unity, the number of stages goes to infinity. When an azeotrope is present in the system, it puts a limit on the achievable separation. In extractive distillation, a third component, called an entrainer (or solvent), is added to the system to increase the relative volatility of the most volatile component (MVC). This is accomplished by selecting an entrainer that interacts favorably with the least volatile component (LVC) [1].

When an entrainer (component 3 ) is added to a binary mixture (component 1 is the MVC and component 2 is the LVC), the relative volatility takes the form $\alpha=\left(\gamma_{1} P_{1}^{\text {sat }}\right) /\left(\gamma_{2} P_{2}^{\text {sat }}\right)$, where we have assumed the vapor phase is an ideal gas and the Poynting correction is negligible. The term $P_{1}^{\text {sat }} / P_{2}^{\text {sat }}$ is the ratio of pure component vapor pressures, which is only a function of temperature. The effect of the entrainer is therefore to alter the activity coefficients, $\gamma_{1}$ and $\gamma_{2}$, leading to the definition of the selectivity $S=\gamma_{1} / \gamma_{2}$. While $\gamma_{1}$ and $\gamma_{2}$ are composition dependent quantities, $S$ generally increases with increasing entrainer composition, reaching a maximum in the pure entrainer limit [2-4]. For early stage process design and conceptualization, it is common to, therefore, consider the limiting selectivity:

$$
S^{\infty}=\frac{\gamma_{1,3}^{\infty}}{\gamma_{2,3}^{\infty}}
$$


which is the ratio of the limiting activity coefficients of component 1 and 2 in the entrainer. Methods are available for the prediction $\gamma_{1,3}^{\infty}$ and $\gamma_{2,3}^{\infty}$, further motivating the use of $S^{\infty}$ to screen and rank entrainer candidates [4-7]. The use of $S^{\infty}$ is additionally motivated physically as it compares directly the intermolecular interactions of the MVC (component 1) and the LVC (component 2) with the entrainer (component 3). In addition to high selectivity, it is desirable to select an entrainer with very low volatility to facilitate separation from the distillation products.

Room temperature ionic liquids (ILs) have received tremendous attention for use as replacement solvents in a wide range of industrial processes [8,9], and are particularly well-suited to use an entrainers in extractive distillation processes $[5,10-23]$. The cation and anion may be changed and modified to tune their chemical and physical properties, and can thus be used to tune $S$. Additionally, due to their ionic nature, ILs have negligible vapor pressures facilitating recovery.

Previous studies have demonstrated that the solvation of molecular solutes in pure ILs can exhibit unique phase behavior [24-26]. In the study of solubility of pharmaceuticals, solubility extremum (and hence, extremum in activity coefficients) have been observed in binary solvents [27]. If we take the IL (entrainer) and MVC (or LVC) to be a binary mixture, we suspect similar behavior may exist, causing the activity coefficient of the LVC (or MVC) to go through an extremum at an intermediate IL composition. The implication of this would be the appropriateness of $S^{\infty}$ to screen and rank ILs as entrainer candidates.

As a result, in the present study, we investigate the ability to use $S^{\infty}$ (or limiting activity coefficients) to screen ILs as entrainer candidates for homogeneous extractive distillation processes. We analyze four recently studied systems which all exhibit a minimum boiling azeotrope: ethanol(1)/water(2), tetrahydrofuran(1)/ethanol(2), methyl acetate(1)/methanol(2) and ethyl acetate(1)/ethanol(2) [11-17]. For all of the systems studied, we use binary interaction parameters for the NRTL (non-random, two-liquid) equation provided in the original publications, allowing us to calculate both composition dependent and limiting activity coefficients for the MVC and LVC in the ternary mixture formed by the addition of IL [28].

Our analysis follows the work of Brandani [29] who, for binary systems, demonstrated that limiting activity coefficients could be used with the Intermediate Value Theorem [30] to identify mono-azeotropic systems. Here, we extend the method to ternary systems, and obtain $S^{\infty}$ as a limiting condition. We find that while for many cases $S^{\infty}$ can be used to properly rank ILs, its use is not always appropriate. One should instead consider use of composition dependent activity coefficients.

We emphasize that in the present study, we provide a thermodynamic assessment of the suitability of $S^{\infty}$ to screen ionic liquid entrainers for homogeneous extractive distillation processes. In the screening of IL candidates, it is important that additional properties be considered, such as miscibility, stability and viscosity [20-23,31]. While Momoh [32] and co-workers did not consider the use of ILs, they did find that $S^{\infty}$ did not correlate well with the annual operating cost of the process. This may be in part due to the limitation of using $S^{\infty}$ as will be explored here, but also is due to the importance of the inclusion of additional properties.

\section{Theory}

\subsection{Binary System}

For a binary system at vapor/liquid equilibrium, assuming the vapor phase is an ideal gas and the Poynting correction is negligible, the iso-fugacity condition can be written as [28]:

$$
\begin{aligned}
& x_{1} \gamma_{1}\left(T, x_{1}\right) P_{1}^{\text {sat }}(T)=y_{1} P \\
& x_{2} \gamma_{2}\left(T, x_{1}\right) P_{2}^{\text {sat }}(T)=y_{2} P
\end{aligned}
$$

where $x_{1}$ and $x_{2}$ are the liquid phase mole fracs of component 1 and 2, respectively, $y_{1}$ and $y_{2}$ are the vapor phase mole fracs of component 1 and 2 , respectively, $P$ is the pressure, $P_{1}^{\text {sat }}$ and $P_{2}^{\text {sat }}$ are the pure 
component vapor pressures at the equilibrium temperature $T$, and $\gamma_{1}$ and $\gamma_{2}$ are the Lewis/Randall or Raoult's law normalized activity coefficients of component 1 and 2, respectively. We will adopt the standard assumption that $\gamma_{1}$ and $\gamma_{2}$ are independent of pressure. Throughout our analysis, component 1 will correspond to the MVC, and component 2 will correspond to the LVC. We identify the MVC and LVC using the pure component vapor pressures $\left(P_{1}^{\text {sat }}>P_{2}^{\text {sat }}\right)$. From Equation (2) we define the $K$-value of component $i$ as:

$$
K_{i}=\frac{y_{i}}{x_{i}}=\frac{\gamma_{i}\left(T, x_{1}\right) P_{i}^{\text {sat }}(T)}{P}
$$

where $i=\{1$ or 2$\}$, and the relative volatility as:

$$
\alpha\left(T, x_{1}\right)=\frac{K_{1}}{K_{2}}=\frac{y_{1} / x_{1}}{y_{2} / x_{2}}=\frac{\gamma_{1}\left(T, x_{1}\right)}{\gamma_{2}\left(T, x_{1}\right)} \frac{P_{1}^{\text {sat }}(T)}{P_{2}^{\text {sat }}(T)}
$$

where by convention $\alpha$ is defined as the ratio of $K$-values of the MVC relative to the LVC. In the design of vapor /liquid separation processes (i.e., distillation), the greater the deviation of $\alpha$ from unity the easier the separation [1,33]. When $\alpha>1$ the MVC is concentrated in the vapor phase, when $\alpha<1$ the LVC is concentrated in the vapor phase, and when $\alpha=1$ no separation is possible.

In the present study, we will consider only isothermal vapor/liquid equilibrium (Pxy) involving binary systems that exhibit a single azeotrope. At an azeotrope, $x_{1}=y_{1}$ and $x_{2}=y_{2}$ leading to the relationship:

$$
\alpha\left(T, x_{1}^{\text {azeo }}\right)=1=\frac{\gamma_{1}\left(T, x_{1}^{\text {azeo }}\right)}{\gamma_{2}\left(T, x_{1}^{\text {azeo }}\right)} \frac{P_{1}^{\text {sat }}(T)}{P_{2}^{\text {sat }}(T)}
$$

where the superscript "azeo" is used to indicate properties at the azeotrope.

Of central importance to the isothermal case is that $P_{1}^{\text {sat }}$ and $P_{2}^{\text {sat }}$ are constant, and having assumed $\gamma_{1}$ and $\gamma_{2}$ are independent of pressure, $\gamma_{1}$ and $\gamma_{2}$ are therefore only functions of composition. Working with Lewis/Randall normalized activity coefficients, we recall the limiting conditions. First, in the infinite dilution limit, the deviations from ideality will be greatest. For a system that exhibits a minimum boiling azeotrope (positive deviations from Raoult's law, $\gamma_{i}>1$ ), this will correspond to values of $\gamma_{i, j}^{\infty}$ that are greater than 1 and a maximum, where the subscript notation " $i, j$ " is used to indicate $i$ is infinitely dilute in $j$. Knowing this, we consider the limiting conditions of Equation (5).

In the limit that $x_{1} \rightarrow 0$ and $x_{2} \rightarrow 1, \gamma_{1} \rightarrow \gamma_{1,2}^{\infty}$ and $\gamma_{2} \rightarrow 1$. In the context of Equation (5), $\gamma_{1} / \gamma_{2} \rightarrow \gamma_{1,2}^{\infty}$. For a system that exhibits a minimum boiling azeotrope, $\gamma_{1,2}^{\infty}$ will be larger than the corresponding value at the azeotrope composition, and $\gamma_{2}=1$ will be less than the corresponding value at the azeotropic composition. As a result, for a system with a minimum boiling azeotrope:

$$
\alpha\left(T, x_{1} \rightarrow 0\right)=\gamma_{1,2}^{\infty}(T) \frac{P_{1}^{\text {sat }}(T)}{P_{2}^{\text {sat }}(T)}>1
$$

Considering next the limit that $x_{1} \rightarrow 1$ and $x_{2} \rightarrow 0, \gamma_{1} \rightarrow 1$ and $\gamma_{2} \rightarrow \gamma_{2,1}^{\infty}$. This leads to $\gamma_{1} / \gamma_{2} \rightarrow 1 / \gamma_{2,1}^{\infty}$. For a system that exhibits a minimum boiling azeotrope, $\gamma_{1}=1$ will be less than the corresponding value at the azeotrope composition, and $\gamma_{2,1}^{\infty}$ will be larger than the corresponding value at the azeotrope composition. As a result, for a system with a minimum boiling azeotrope:

$$
\alpha\left(T, x_{1} \rightarrow 1\right)=\frac{1}{\gamma_{2,1}^{\infty}(T)} \frac{P_{1}^{\text {sat }}(T)}{P_{2}^{\text {sat }}(T)}<1
$$

Putting it together, for a system with a minimum boiling azeotrope:

$$
\alpha\left(T, x_{1} \rightarrow 0\right)>1>\alpha\left(T, x_{1} \rightarrow 1\right)
$$


This tells us that, at low concentrations of the MVC, $\alpha>1$ and the MVC will be concentrated in the vapor phase. Then, past the azeotropic composition, $\alpha<1$ and the LVC will be concentrated in the vapor phase. Further, since $T$ is constant and $\alpha$ is a continuous function with respect to $x_{1}$, the Intermediate Value Theorem states that there exist a value of $x_{1}$ such that $\alpha=1$, confirming the existence of an azeotrope [30].

Using the same analysis, we can obtain an equivalent expression for the case of a maximum boiling azeotrope. The difference is for a system that exhibits a maximum boiling azeotrope (negative deviations from Raoult's law, $\gamma_{i}<1$ ), the limiting conditions will correspond to values of $\gamma_{i, j}^{\infty}$ that are less than 1 and a minimum. This results in the following expression for a system with a maximum boiling azeotrope:

$$
\alpha\left(T, x_{1} \rightarrow 0\right)<1<\alpha\left(T, x_{1} \rightarrow 1\right)
$$

We find that for the case of a maximum boiling azeotrope, at low concentrations of the MVC, $\alpha<1$ and the LVC will be concentrated in the vapor phase. Then, past the azeotropic composition, $\alpha>1$ and the MVC will be concentrated in the vapor phase.

Equations (8) and (9) can equivalently be re-cast as:

$$
\gamma_{2,1}^{\infty}(T)>\frac{P_{1}^{\text {sat }}(T)}{P_{2}^{\text {sat }}(T)}>\frac{1}{\gamma_{1,2}^{\infty}(T)}
$$

and

$$
\gamma_{2,1}^{\infty}(T)<\frac{P_{1}^{\text {sat }}(T)}{P_{2}^{\text {sat }}(T)}<\frac{1}{\gamma_{1,2}^{\infty}(T)}
$$

These expressions were first proposed for binary mono-azeotropic systems by Brandani [29] 44 years ago. Subsequently, Shulgin et al. [34] used only the inequality for the $\operatorname{LVC}\left(\gamma_{2,1}^{\infty}\right)$ for minimum boiling azeotropes and the inequality of the $\operatorname{MVC}\left(\gamma_{1,2}^{\infty}\right)$ for maximum boiling azeotropes along with pure component vapor pressures to classify all types of azeotropic and zeotropic behavior of subcritical homogeneous binary mixtures. Missen [35] has recently provided an alternative derivation where he too uses only the inequality for the LVC for minimum boiling azeotropes and the inequality of the MVC for maximum boiling azeotropes to identify the presence of azeotropes in binary systems. With a parameterized excess Gibbs free energy model, Missen [36] later showed how the coordinates of the azeotrope could be located. In the absence of an azeotrope, $\alpha>1$ for all $x_{1}$. Therefore, the requirement that $\alpha\left(T, x_{1} \rightarrow 1\right)<1$ would be sufficient to predict the presence of a minimum boiling azeotrope, consistent with use of only $\gamma_{2,1}^{\infty}$ by Missen [35]. Likewise, the requirement of $\alpha\left(T, x_{1} \rightarrow 0\right)<1$ would be sufficient to predict the presence of a maximum boiling azeotrope, consistent with use of only $\gamma_{1,2}^{\infty}$ by Missen [35]. We will maintain both criteria as both will be important as we discuss breaking azeotropes.

\subsection{Adding IL as Entrainer}

While Equation (8) was derived for the case of a binary system exhibiting a single azeotrope, for the case of selecting an IL as an entrainer, an equivalent expression is applicable. ILs are unique in that they are virtually non-volatile, and therefore, we can assume that they are not present in the vapor-phase [37-40]. The presence of IL adds an additional degree of freedom to our system, the liquid phase mole frac of IL $\left(x_{3}\right)$, but it does not add an additional phase-equilibria expressions. In the presence of the IL, our iso-fugacity expression becomes:

$$
\begin{aligned}
& x_{1}^{0}\left(1-x_{3}\right) \gamma_{1}\left(T, x_{1}^{0}, x_{3}\right) P_{1}^{\mathrm{sat}}(T)=y_{1} P \\
& x_{2}^{0}\left(1-x_{3}\right) \gamma_{2}\left(T, x_{1}^{0}, x_{3}\right) P_{2}^{\mathrm{sat}}(T)=y_{2} P
\end{aligned}
$$


where $x_{3}$ is the mole frac of IL added as an entrainer, and $x_{1}^{0}$ and $x_{2}^{0}$ correspond to IL free mole fracs of components 1 and 2, respectively, where $x_{1}=x_{1}^{0}\left(1-x_{3}\right), x_{2}=x_{2}^{0}\left(1-x_{3}\right)$, and $x_{1}^{0}+x_{2}^{0}=1$. The relative volatility takes the form:

$$
\alpha\left(T, x_{1}^{0}, x_{3}\right)=\frac{\gamma_{1}\left(T, x_{1}^{0}, x_{3}\right)}{\gamma_{2}\left(T, x_{1}^{0}, x_{3}\right)} \frac{P_{1}^{\text {sat }}(T)}{P_{2}^{\text {sat }}(T)}
$$

and if the azeotrope persists in the presence of the IL at fixed mole frac $x_{3}$, then at the azeotrope:

$$
\alpha\left(T, x_{1}^{0, \text { azeo }}, x_{3}\right)=1=\frac{\gamma_{1}\left(T, x_{1}^{0, \text { azeo }}, x_{3}\right)}{\gamma_{2}\left(T, x_{1}^{0, \text { azeo }}, x_{3}\right)} \frac{P_{1}^{\text {sat }}(T)}{P_{2}^{\text {sat }}(T)}
$$

Following our discussion of binary systems, for an isothermal system with constant $x_{3}$, the relationship:

$$
\alpha\left(T, x_{1}^{0} \rightarrow 0, x_{3}\right)>1>\alpha\left(T, x_{1}^{0} \rightarrow 1, x_{3}\right)
$$

confirms the presence of a minimum boiling azeotrope over the range $0>x_{1}^{0}>1$ per the Intermediate Value Theorem. Likewise, for the case of a maximum boiling azeotrope we have:

$$
\alpha\left(T, x_{1}^{0} \rightarrow 0, x_{3}\right)<1<\alpha\left(T, x_{1}^{0} \rightarrow 1, x_{3}\right)
$$

This leads to a set of simple design criteria. For a binary system that exhibits an azeotrope, the IL and IL concentration will be chosen such that Equation (15) or (16) is no longer true. This happens when the value of $\alpha$ in the limit that $x_{1}^{0} \rightarrow 0$ and $x_{1}^{0} \rightarrow 1$ are both greater than 1 or are both less than 1 . Specifically, the mole frac of IL $\left(x_{3}\right)$ is sufficient to break the azeotrope when either of the following expressions is true:

$$
\alpha\left(T, x_{1}^{0} \rightarrow 0, x_{3}\right)>1 \wedge \alpha\left(T, x_{1}^{0} \rightarrow 1, x_{3}\right)>1
$$

or

$$
\alpha\left(T, x_{1}^{0} \rightarrow 0, x_{3}\right)<1 \wedge \alpha\left(T, x_{1}^{0} \rightarrow 1, x_{3}\right)<1
$$

In general we suspect the first criteria to be the one of interest. We additionally emphasize this is only applicable to systems that exhibit a single azeotrope. We will see cases where the addition of IL creates a poly-azeotropic system. Our motivation here is to evaluate the use of simplified expressions to quickly evaluate the suitability of an IL as an entrainer.

\subsection{Using Limiting Selectivity}

Following our discussion (Equations (8) and (17)), for a binary system that exhibits a minimum boiling azeotrope, the addition of IL will break the azeotrope if

$$
\alpha\left(T, x_{1}^{0} \rightarrow 1, x_{3} \rightarrow 0\right)<1<\alpha\left(T, x_{1}^{0} \rightarrow 1, x_{3}\right)
$$

In this expression, $\alpha$ is only a function of $x_{3}$. Since $\alpha$ is a continuous function of $x_{3}$, per the Intermediate Value Theorem, if

$$
\alpha\left(T, x_{1}^{0} \rightarrow 1, x_{3} \rightarrow 0\right)<1<\alpha\left(T, x_{1}^{0} \rightarrow 1, x_{3} \rightarrow 1\right)
$$

then there exist a value of $x_{3}$ between 0 and 1 for which Equation (19) is true. Put differently, if $\alpha\left(T, x_{1}^{0} \rightarrow 1, x_{3} \rightarrow 1\right)>1$, then the IL is capable of breaking the azeotrope. Using the definition of $\alpha$ : 


$$
\alpha\left(T, x_{1}^{0} \rightarrow 1, x_{3} \rightarrow 1\right)=\frac{\gamma_{1,3}^{\infty}(T)}{\gamma_{2,3}^{\infty}(T)} \frac{P_{1}^{\text {sat }}(T)}{P_{2}^{\text {sat }}(T)}=S^{\infty}(T) \frac{P_{1}^{\text {sat }}(T)}{P_{2}^{\text {sat }}(T)}>1
$$

where $\gamma_{1,3}^{\infty}$ and $\gamma_{2,3}^{\infty}$ correspond to the limiting (or infinite dilution) activity coefficient of component 1 and 2 in pure IL (component 3), respectively, and $S^{\infty}$ is the limiting selectivity.

Equation (21) is interesting because the ratio of $\gamma_{1,3}^{\infty} / \gamma_{2,3}^{\infty}$ corresponds to the limiting selectivity which has long been used to screen entrainer candidates [2-5]. It's basis stems from Equation (13). For an isothermal system, $P_{1}^{\text {sat }} / P_{2}^{\text {sat }}$ is constant. Therefore, for a fixed composition of component 1 and 2 , the only way to increase $\alpha$ is through the addition of an entrainer (component 3 ). The selectivity (S) is defined as the ratio of $\gamma_{1} / \gamma_{2}$ for a fixed composition of component 1 and 2 , and it has been found that in general $S$ increases with increasing entrainer composition, becoming a maximum in the pure entrainer limit (corresponding to $S^{\infty}$ ) [2-4]. Entrainer candidates are typically ranked using $S^{\infty}$.

We point out that the resulting expressions for $\alpha\left(T, x_{1}^{0} \rightarrow 1, x_{3} \rightarrow 1\right)$ and $\alpha\left(T, x_{1}^{0} \rightarrow 0, x_{3} \rightarrow 1\right)$ are equivalent, so that Equation (21) is additionally applicable when breaking a maximum boiling azeotrope where the result is to concentrate the MVC in the vapor phase $(\alpha>1)$. Likewise, if we desired to concentrate the LVC in the vapor phase $(\alpha<1)$, for both cases we would change $>1$ to $<1$.

We remind the reader that the derivations of the present study all originated with the assumption that the system exhibits a single azeotrope. An IL may therefore be capable of breaking an azeotrope even if it does not satisfy the expressions derived here. This scenario is possible, as for example observed in solubility extremum of non-electrolyte solids in binary solvents [27]. The goal of the present study is to evaluate the utility of these simplified expressions for screening IL candidates.

\section{Application}

We will analyze four recently studied systems which all exhibit a minimum boiling azeotrope: ethanol(1)/water(2), tetrahydrofuran(1)/ethanol(2), methyl acetate(1)/methanol(2) and ethyl acetate(1)/ethanol(2) [11-17]. For all of the systems studied, we use binary interaction parameters for the NRTL (non-random, two-liquid) equation provided in the original publications [28]. All of the binary interaction parameters for the binary systems were fit directly to binary vapor/liquid equilibrium data, and the parameters involving the ionic liquids were fit to ternary vapor/liquid equilibrium data [11-17]. All of the vapor pressures at the temperatures of interest were taken from ref. [41].

\subsection{Ethanol(1)/Water(2)}

We consider first the binary system of ethanol(1)/water(2) recently studied by Ge et al. [11]. In that work they considered use of either the 1-ethyl-3-methylimidazolium $\left(\left[\mathrm{C}_{2} \mathrm{mim}\right]^{+}\right)$or 1-butyl-3-methylimidazolium $\left(\left[\mathrm{C}_{4} \mathrm{mim}\right]^{+}\right)$cation with one of the following anions: tetrafluoroborate $\left(\left[\mathrm{BF}_{4}\right]^{-}\right)$, dicyanamide $\left([\mathrm{DCA}]^{-}\right)$, chloride $\left([\mathrm{Cl}]^{-}\right)$, or acetate $\left(\left[\mathrm{CH}_{3} \mathrm{COO}\right]^{-}\right)$. Here, we consider only use of $\left[\mathrm{C}_{4} \mathrm{mim}\right]^{+}$. The study of Ge et al. [11] was conducted at $100 \mathrm{kPa}$. The calculations here were performed at approximately the temperature of the azeotrope, $351 \mathrm{~K}$.

First, at $351 \mathrm{~K}$ we calculated the minimum mole frac of IL $\left(x_{3}\right)$ needed to break the azeotrope. This was accomplished by calculating the minimum $x_{3}$ necessary so that $\alpha>1$ or $\alpha<1$ for all values of $x_{1}^{0}$ over the range 0 to 1 . We take theses values to be the correct, reference values. We compared the reference values to use of the proposed Equation (17) where we solved for the first value of $x_{3}$ where $\alpha\left(T, x_{1}^{0} \rightarrow 1, x_{3}\right)=1$. The computed values are tabulated in Table 1 , and are all in excellent agreement. 
Table 1. The minimum mole frac of IL needed to break the azeotrope $\left(x_{3}^{\min }\right)$ for the binary system ethanol(1)/water(2) at $351 \mathrm{~K}$. The ILs correspond to the $\left[\mathrm{C}_{4} \mathrm{mim}\right]^{+}$cation with the indicated anion. The reference (ref) values were computed as the minimum $x_{3}$ necessary so that $\alpha>1$ or $\alpha<1$ for all values of $x_{1}^{0}$ over the range 0 to 1 . This is compared to calculations using Equation (17) where we solve for the first value of $x_{3}$ where $\alpha\left(T, x_{1}^{0} \rightarrow 1, x_{3}\right)=1$.

\begin{tabular}{ccc}
\hline & $x_{3}^{\min }$ \\
IL Anion & Equation (17) & Ref. \\
\hline$\left[\mathrm{CH}_{3} \mathrm{COO}\right]^{-}$ & 0.0144 & 0.0144 \\
{$\left[\mathrm{BF}_{4}\right]^{-}$} & 0.0249 & 0.0249 \\
{$[\mathrm{DCA}]^{-}$} & 0.0255 & 0.0255 \\
{$[\mathrm{Cl}]^{-}$} & 0.0288 & 0.0289 \\
\hline
\end{tabular}

Next, we consider plots of $\ln \alpha\left(T, x_{1}^{0} \rightarrow 1, x_{3}\right)$ and $\ln \alpha\left(T, x_{1}^{0} \rightarrow 0, x_{3}\right)$ versus $x_{3}$ in Figure 1. Ethanol(1)/water(2) exhibits a minimum boiling azeotrope, so in the absence of IL $\left(x_{3}=0\right)$, $\alpha\left(T, x_{1}^{0} \rightarrow 0, x_{3} \rightarrow 0\right)>1>\alpha\left(T, x_{1}^{0} \rightarrow 1, x_{3} \rightarrow 0\right)$. We find that only a small amount of IL is needed to increase the value of $\alpha\left(T, x_{1}^{0} \rightarrow 1, x_{3}\right)$ to break the azeotrope. With the anions $\left[\mathrm{CH}_{3} \mathrm{COO}^{-},\left[\mathrm{BF}_{4}\right]^{-}\right.$ and [DCA] $^{-}$, the IL breaks the azeotrope for all $x_{3}$ greater than the minimum mole frac of IL needed. On the other hand, this is not the case with the $[\mathrm{Cl}]^{-}$anion. In fact, at $x_{3}=0.5458$, we have the formation of a maximum boiling azeotrope. The azeotrope is then quickly broken $\left(x_{3}=0.6052\right)$, after which the LVC is concentrated in the vapor phase. The implication of this is that it sets bounds on the operating range of $x_{3}$.

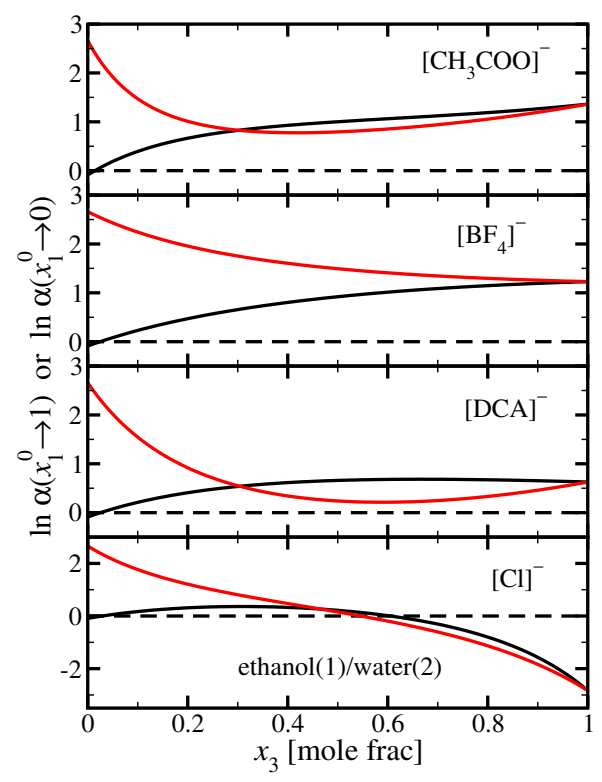

Figure 1. Plot of the limiting relative volatility ( $\alpha$ when $x_{1}^{0} \rightarrow 0$ and $x_{1}^{0} \rightarrow 1$ ) as a function of IL mole frac $\left(x_{3}\right)$ for the binary system ethanol(1)/water(2) at $351 \mathrm{~K}$. The ILs correspond to the $\left[\mathrm{C}_{4} \mathrm{mim}\right]^{+}$cation with the indicated anion, and the horizontal dashed line corresponds to $\ln \alpha=0(\alpha=1)$, and is drawn as a reference.

Consider, next, the values in the limit of $x_{3} \rightarrow 1$, where the curves intersect the right-axis. As already shown, the limiting values are identical. Using these values, we would predict that the anions $\left[\mathrm{CH}_{3} \mathrm{COO}^{-},\left[\mathrm{BF}_{4}\right]^{-}\right.$and $[\mathrm{DCA}]^{-}$break the azeotrope with $\alpha>1$. Comparing the numerical values, we would rank the anions as $\left[\mathrm{CH}_{3} \mathrm{COO}^{-}>\left[\mathrm{BF}_{4}\right]^{-}>[\mathrm{DCA}]^{-}\right.$, which is consistent with the ranking based on the minimum $x_{3}$ needed. We would additionally predict that $[\mathrm{Cl}]^{-}$would break the azeotrope, and it would be ranked last. However, the limiting value predicts that $\alpha<1$ and the LVC will be concentrated in the vapor phase. This is in fact only true for large values of $x_{3}$. 
Therefore, for this case, we find that the value in the limit of $x_{3} \rightarrow 1$, which would correspond to the use of $S^{\infty}$, does not capture the complete phase behavior of the system.

Last, in Figure 2 we plot $\ln \alpha\left(T, x_{1}^{0}, x_{3}\right)$ versus $x_{1}^{0}$ for fixed values of $x_{3}$ with the $\left[\mathrm{CH}_{3} \mathrm{COO}\right]^{-}$ and $[\mathrm{Cl}]^{-}$anions. With the anion $\left[\mathrm{CH}_{3} \mathrm{COO}\right]^{-}$, we find that for large values of $x_{1}^{0}, \alpha$ increases with increasing $x_{3}$. At the same time, for small values of $x_{1}^{0}, \alpha$ decreases with increasing $x_{3}$. The trend with the $[\mathrm{Cl}]^{-}$anion is similar, except at higher concentrations of $x_{3}$, we observe a large decrease in $\alpha$. Additionally, we find that at low concentrations of $x_{3}$ the performance of $[\mathrm{Cl}]^{-}$is comparable to $\left[\mathrm{CH}_{3} \mathrm{COO}\right]^{-}$and could be a suitable entrainer under these conditions. This would not be captured considering only the limit of $x_{3} \rightarrow 1$.

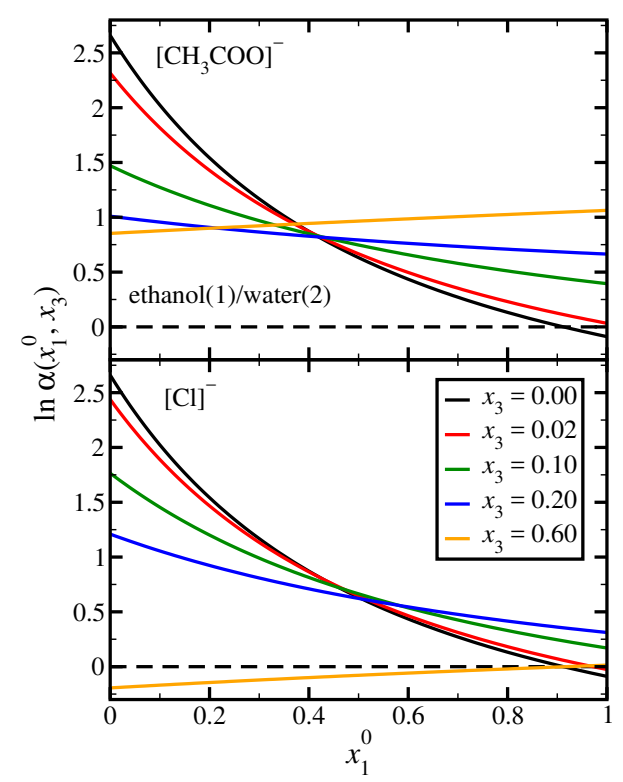

Figure 2. Plot of the relative volatility $(\alpha)$ as a function of the IL free mole frac of ethanol $\left(x_{1}^{0}\right)$ for the binary system ethanol(1)/water(2) at $351 \mathrm{~K}$. The lines correspond to different, fixed values of $x_{3}$, as indicated in the legend. The horizontal dashed line corresponds to $\ln \alpha=0(\alpha=1)$, and is drawn as a reference. The top pane corresponds to use of the IL $\left[\mathrm{C}_{4} \mathrm{mim}\right]\left[\mathrm{CH}_{3} \mathrm{COO}\right]$ and the bottom pane corresponds to $\left[\mathrm{C}_{4} \mathrm{mim}\right][\mathrm{Cl}]$.

\subsection{Tetrahydrofuran(1)/Ethanol(2)}

We consider, next, the binary system of tetrahydrofuran(1)/ethanol(2) recently studied by Cao et al. [12]. In that work they considered use of $\left[\mathrm{C}_{4} \mathrm{mim}\right]^{+}$with the $\left[\mathrm{BF}_{4}\right]^{-}$and $[\mathrm{DCA}]^{-}$anions, and 1-octyl-3-methylimidazolium $\left(\left[\mathrm{C}_{8} \mathrm{mim}\right]^{+}\right)$with the $\left[\mathrm{BF}_{4}\right]^{-}$anion. The study of Cao et al. [12] was conducted at $101.3 \mathrm{kPa}$. The calculations here were performed at approximately the temperature of the azeotrope, $339 \mathrm{~K}$.

In Table 2, we compare the calculated minimum mole frac of IL $\left(x_{3}\right)$ needed to break the azeotrope using reference calculations to that using Equation (17). We again find the values are in excellent agreement. In Figure 3 we plot $\ln \alpha\left(T, x_{1}^{0} \rightarrow 1, x_{3}\right)$ and $\ln \alpha\left(T, x_{1}^{0} \rightarrow 0, x_{3}\right)$ versus $x_{3}$. In all cases we find that the IL is able to break the azeotrope with a small value of $x_{3}$, and the azeotrope remains broken up to the limit that $x_{3} \rightarrow 1$. If we were to consider only the values in the limit that $x_{3} \rightarrow 1$, we would predict that the ILs are all capable of breaking the azeotrope with $\alpha>1$. Also, comparing the numerical values, we would rank the ILs as $\left[\mathrm{C}_{4} \mathrm{mim}\right][\mathrm{DCA}]>\left[\mathrm{C}_{4} \mathrm{mim}\right]\left[\mathrm{BF}_{4}\right]>\left[\mathrm{C}_{8} \mathrm{mim}\right]\left[\mathrm{BF}_{4}\right]$, in agreement with ranking based on the minimum mole frac of $\operatorname{IL}\left(x_{3}\right)$ needed to break the azeotrope. 
Table 2. The minimum mole frac of IL needed to break the azeotrope $\left(x_{3}^{\min }\right)$ for the binary system tetrahydrofuran(1)/ethanol(2) at $339 \mathrm{~K}$ using the indicated IL. The reference (ref) values were computed as the minimum $x_{3}$ necessary so that $\alpha>1$ or $\alpha<1$ for all values of $x_{1}^{0}$ over the range 0 to 1 . This is compared to calculations using Equation (17) where we solve for the first value of $x_{3}$ where $\alpha\left(T, x_{1}^{0} \rightarrow 1, x_{3}\right)=1$.

\begin{tabular}{ccc}
\hline IL Anion & \multicolumn{2}{c}{$\boldsymbol{x}_{3}^{\text {min }}$} \\
\hline$\left[\mathrm{C}_{4} \mathrm{mim}\right]\left[\mathrm{BF}_{4}\right]$ & 0.0065 & 0.0061 \\
{$\left[\mathrm{C}_{8} \mathrm{mim}\right]\left[\mathrm{BF}_{4}\right]$} & 0.0089 & 0.0087 \\
{$\left[\mathrm{C}_{4} \mathrm{mim}\right][\mathrm{DCA}]$} & 0.0007 & 0.0007 \\
\hline
\end{tabular}

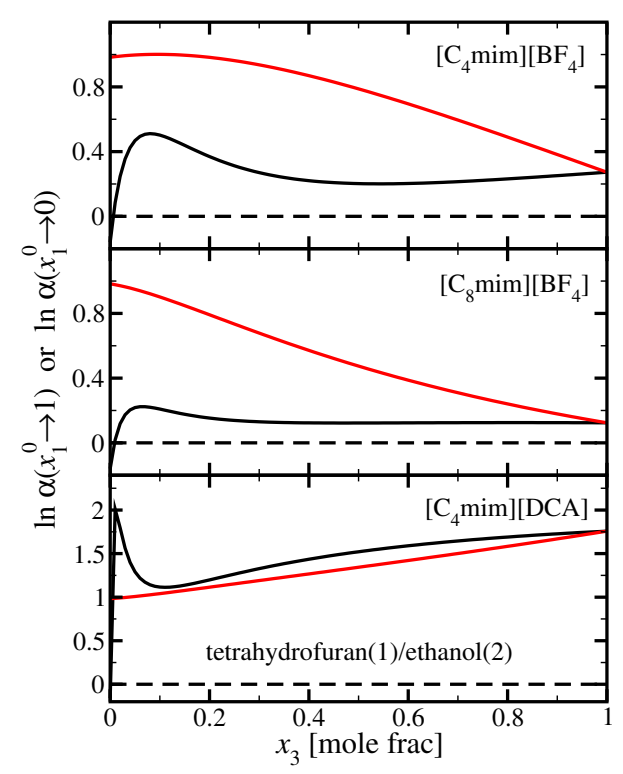

Figure 3. Plot of the limiting relative volatility ( $\alpha$ when $x_{1}^{0} \rightarrow 0$ and $x_{1}^{0} \rightarrow 1$ ) as a function of IL mole frac $\left(x_{3}\right)$ for the binary system tetrahydrofuran(1)/ethanol(2) at $339 \mathrm{~K}$. The horizontal dashed line corresponds to $\ln \alpha=0(\alpha=1)$ and is drawn as a reference, and the IL is indicated in the figure panes.

\subsection{Methyl Acetate(1)/Methanol(2)}

We consider, next, the binary system of methyl acetate(1)/methanol(2) recently studied in refs. [13-16]. Refs. $[13,15,16]$ were conducted at $101.3 \mathrm{kPa}$, while ref. [14] was conducted at $327.31 \mathrm{~K}$. The approximate temperature of the azeotrope at $101.3 \mathrm{kPa}$ is $327.31 \mathrm{~K}$, so here we performed all calculations at 327.31 K. The studies considered 1-ethyl-3-methylimidazolium $\left(\left[\mathrm{C}_{2} \mathrm{mim}\right]^{+}\right)$with the $\left[\mathrm{CH}_{3} \mathrm{COO}\right]^{-}$ and thiocyanate $\left([\mathrm{SCN}]^{-}\right)$anions, $\left[\mathrm{C}_{4} \mathrm{mim}\right]^{+}$with the bromide $\left([\mathrm{Br}]^{-}\right)$and $[\mathrm{Cl}]^{-}$anions, $\left[\mathrm{C}_{8} \mathrm{mim}\right]^{+}$ with the hexafluorophosphate $\left(\left[\mathrm{PF}_{6}\right]^{-}\right)$anion, 1-butyl-1-methylpyrrolidinium $\left(\left[\mathrm{C}_{4} \mathrm{C}_{1} \mathrm{pyr}\right]^{+}\right)$with the [DCA $^{-}$anion, and 1-(2-chloroethyl)-3-methylimidazolium $\left(\left[\mathrm{ClC}_{2} \mathrm{mim}\right]^{+}\right)$with the $[\mathrm{Cl}]^{-}$anion.

In Table 3 we compare the calculated minimum mole frac of IL $\left(x_{3}\right)$ needed to break the azeotrope using reference calculations to that using Equation (17). We again find the values are in excellent agreement, and for the case of $\left[\mathrm{C}_{8} \mathrm{mim}\right]\left[\mathrm{PF}_{6}\right]$ we correctly predict that we break the azeotrope with $\alpha<1$.

In Figure 4 , we plot $\ln \alpha\left(T, x_{1}^{0} \rightarrow 1, x_{3}\right)$ and $\ln \alpha\left(T, x_{1}^{0} \rightarrow 0, x_{3}\right)$ versus $x_{3}$ for $\left[\mathrm{C}_{4} \mathrm{mim}\right][\mathrm{Br}]$, $\left[\mathrm{C}_{4} \mathrm{mim}\right][\mathrm{Cl}],\left[\mathrm{C}_{4} \mathrm{C}_{1} \mathrm{pyr}\right][\mathrm{DCA}]$, and $\left[\mathrm{ClC}_{2} \mathrm{mim}\right][\mathrm{Cl}]$. For all cases, we find that the azeotrope is broken with relatively small values of $x_{3}$, and remains broken up to the limit that $x_{3} \rightarrow 1$. We find that both $\left[\mathrm{C}_{4} \mathrm{mim}\right][\mathrm{Br}]$ and $\left[\mathrm{C}_{4} \mathrm{mim}\right][\mathrm{Cl}]$, exhibit unique behavior in that $\ln \alpha\left(T, x_{1}^{0} \rightarrow 1, x_{3}\right)$ and $\ln \alpha\left(T, x_{1}^{0} \rightarrow 0, x_{3}\right)$ increases rapidly in the limit that $x_{3} \rightarrow 1$. If we were to use only the limiting values $\left(x_{3} \rightarrow 1\right)$ to rank and screen the ILs, the ranking would differ than using the minimum mole frac of IL 
needed to break the azeotrope. In fact we find that while $\left[\mathrm{C}_{4} \mathrm{C}_{1}\right.$ pyr][DCA] has the smallest value in the limit that $x_{3} \rightarrow 1$, it requires the least amount of IL to break the azeotrope.

Table 3. The minimum mole frac of IL needed to break the azeotrope $\left(x_{3}^{\min }\right)$ for the binary system methyl acetate(1)/methanol(2) at $327.31 \mathrm{~K}$ using the indicated IL. The reference (ref) values were computed as the minimum $x_{3}$ necessary so that $\alpha>1$ or $\alpha<1$ for all values of $x_{1}^{0}$ over the range 0 to 1. This is compared to calculations using Equation (17) where we solve for the first value of $x_{3}$ where $\alpha\left(T, x_{1}^{0} \rightarrow 1, x_{3}\right)=1$.

\begin{tabular}{ccc}
\hline IL Anion & $\begin{array}{c}x_{3}^{\text {min }} \\
\text { Equation }(17)\end{array}$ & Ref. \\
\hline$\left[\mathrm{C}_{4}\right.$ mim $][\mathrm{Br}]$ & 0.2307 & 0.2308 \\
{$\left[\mathrm{C}_{4} \mathrm{mim}\right][\mathrm{Cl}]$} & 0.1203 & 0.1203 \\
{$\left[\mathrm{C}_{2}\right.$ mim $]\left[\mathrm{CH}_{3} \mathrm{COO}\right]$} & 0.0953 & 0.0953 \\
{$\left[\mathrm{C}_{2}\right.$ mim $][\mathrm{SCN}]$} & 0.0391 & 0.0398 \\
{$\left[\mathrm{C}_{4} \mathrm{C}_{1} \mathrm{pyr}\right][\mathrm{DCA}]$} & 0.0381 & 0.0419 \\
{$\left[\mathrm{ClC}_{2}\right.$ mim $][\mathrm{Cl}]$} & 0.1823 & 0.1823 \\
{$\left[\mathrm{C}_{8} \mathrm{mim}\right]\left[\mathrm{PF}_{6}\right]$} & 0.3455 & 0.3456 \\
\hline
\end{tabular}

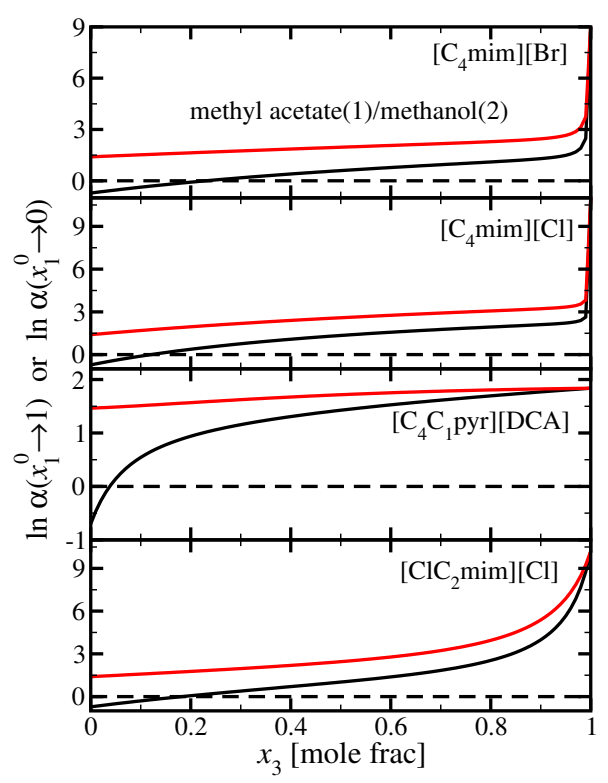

Figure 4. Plot of the limiting relative volatility ( $\alpha$ when $x_{1}^{0} \rightarrow 0$ and $x_{1}^{0} \rightarrow 1$ ) as a function of IL mole frac $\left(x_{3}\right)$ for the binary system methyl acetate $(1) /$ methanol(2) at $327.31 \mathrm{~K}$. The horizontal dashed line corresponds to $\ln \alpha=0(\alpha=1)$ and is drawn as a reference, and the IL is indicated in the figure panes.

In Figure 5, we plot $\ln \alpha\left(T, x_{1}^{0} \rightarrow 1, x_{3}\right)$ and $\ln \alpha\left(T, x_{1}^{0} \rightarrow 0, x_{3}\right)$ versus $x_{3}$ for $\left[\mathrm{C}_{2}\right.$ mim] $\left[\mathrm{CH}_{3} \mathrm{COO}\right]$, $\left[\mathrm{C}_{2} \mathrm{mim}\right][\mathrm{SCN}]$, and $\left[\mathrm{C}_{8} \mathrm{mim}\right]\left[\mathrm{PF}_{6}\right]$. We find that all of the ILs are able to break the azeotrope, with $\left[\mathrm{C}_{8} \mathrm{mim}\right]\left[\mathrm{PF}_{6}\right]$ breaking the azeotrope with $\alpha<1$.

Lastly, in Figure 6, we plot $\ln \alpha\left(T, x_{1}^{0}, x_{3}\right)$ versus $x_{1}^{0}$ for fixed values of $x_{3}$ with $\left[\mathrm{C}_{2} \operatorname{mim}\right][\mathrm{SCN}]$ and $\left[\mathrm{C}_{8} \mathrm{mim}\right]\left[\mathrm{PF}_{6}\right]$. We find that for both small and large values of $x_{1}^{0}, \alpha$ increases with increasing $x_{3}$ for $\left[\mathrm{C}_{2} \mathrm{mim}\right][\mathrm{SCN}]$ and decreases for $\left[\mathrm{C}_{8} \mathrm{mim}\right]\left[\mathrm{PF}_{6}\right]$. This is contrary to the results shown in ethanol(1)/water(2) wherein the behavior was different for large and small values of $x_{1}^{0}$. While for ethanol(1)/water(2) both compounds are able to donate and accept hydrogen bonds, here methyl acetate is an acceptor only. 


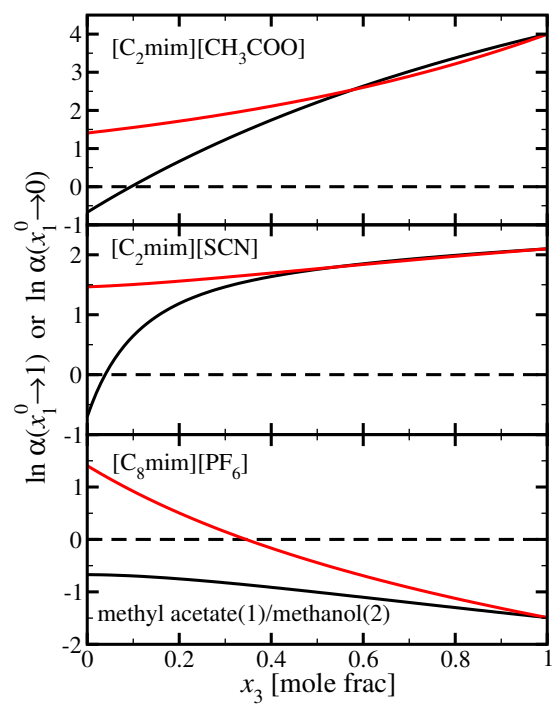

Figure 5. Plot of the limiting relative volatility ( $\alpha$ when $x_{1}^{0} \rightarrow 0$ and $x_{1}^{0} \rightarrow 1$ ) as a function of IL mole frac $\left(x_{3}\right)$ for the binary system methyl acetate(1)/methanol(2) at $327.31 \mathrm{~K}$. The horizontal dashed line corresponds to $\ln \alpha=0(\alpha=1)$ and is drawn as a reference, and the IL is indicated in the figure panes.

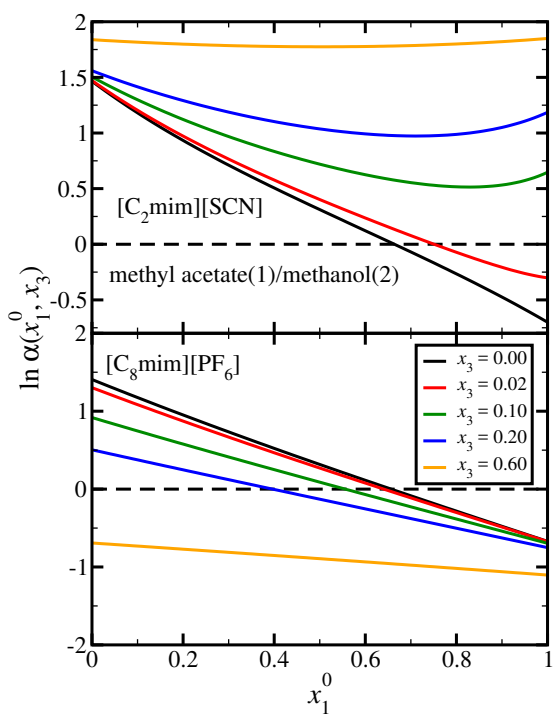

Figure 6. Plot of the relative volatility $(\alpha)$ as a function of the IL free mole frac of methanol $\left(x_{1}^{0}\right)$ for the binary system methyl acetate $(1) /$ methanol(2) at $327.31 \mathrm{~K}$. The lines correspond to different, fixed values of $x_{3}$, as indicated in the legend. The horizontal dashed line corresponds to $\ln \alpha=0(\alpha=1)$, and is drawn as a reference. The top pane corresponds to use of the IL $\left[\mathrm{C}_{2} \mathrm{mim}\right][\mathrm{SCN}]$ and the bottom pane corresponds to $\left[\mathrm{C}_{8} \mathrm{mim}\right]\left[\mathrm{PF}_{6}\right]$.

\subsection{Ethyl Acetate(1)/Ethanol(2)}

The last binary system we will consider is ethyl acetate(1)/ethanol(2) which was recently studied by Andreatta et al. [17]. In that work they considered $\left[\mathrm{C}_{2} \mathrm{mim}\right]^{+}$with methanesulfonate $\left(\left[\mathrm{MeSO}_{3}\right]^{-}\right)$, methylsulfate $\left(\left[\mathrm{MeSO}_{4}\right]^{-}\right)$and bis(trifluoromethylsulfonyl)imide $\left(\left[\mathrm{Tf}_{2} \mathrm{~N}\right]^{-}\right),\left[\mathrm{C}_{4} \mathrm{mim}^{+}\right.$ with trifluoromethanesulfonate $\left(\left[\mathrm{CF}_{3} \mathrm{SO}_{3}\right]^{-}\right)$, 1-hexyl-3-methylimidazolium $\left(\left[\mathrm{C}_{6} \mathrm{mim}\right]^{+}\right)$with $\left[\mathrm{Tf}_{2} \mathrm{~N}\right]^{-}$, and $\left[\mathrm{C}_{4} \mathrm{C}_{1}\right.$ pyr $]\left[\mathrm{Tf}_{2} \mathrm{~N}\right]$. The study was conducted at $313.15 \mathrm{~K}$.

In Table 4 we compare the calculated minimum mole frac of IL $\left(x_{3}\right)$ needed to break the azeotrope using reference calculations to that using Equation (17). We find that the predictions are in good agreement, except for the case of $\left[\mathrm{C}_{2} \mathrm{mim}\right]\left[\mathrm{Tf}_{2} \mathrm{~N}\right]$ and $\left[\mathrm{C}_{6} \operatorname{mim}\right]\left[\mathrm{Tf}_{2} \mathrm{~N}\right]$. 
Table 4. The minimum mole frac of IL needed to break the azeotrope $\left(x_{3}^{\min }\right)$ for the binary system ethyl acetate(1)/ethanol(2) at $313.15 \mathrm{~K}$ using the indicated IL. The reference (ref) values were computed as the minimum $x_{3}$ necessary so that $\alpha>1$ or $\alpha<1$ for all values of $x_{1}^{0}$ over the range 0 to 1 . This is compared to calculations using Equation (17) where we solve for the first value of $x_{3}$ where $\alpha\left(T, x_{1}^{0} \rightarrow 1, x_{3}\right)=1$.

\begin{tabular}{ccc}
\hline IL Anion & $\begin{array}{c}\boldsymbol{x}_{3}^{\text {min }} \\
\text { Equation }(17)\end{array}$ & Ref. \\
\hline$\left[\mathrm{C}_{4} \mathrm{mim}\right]\left[\mathrm{CF}_{3} \mathrm{SO}_{2}\right]$ & 0.0288 & 0.0595 \\
{$\left[\mathrm{C}_{4} \mathrm{C}_{1}\right.$ pyr $]\left[\mathrm{Tf}_{2} \mathrm{~N}\right]$} & 0.6659 & 0.6659 \\
{$\left[\mathrm{C}_{2} \mathrm{mim}\right]\left[\mathrm{MeSO}_{3}\right]$} & 0.0226 & 0.0468 \\
{$\left[\mathrm{C}_{2} \mathrm{mim}\right]\left[\mathrm{MeSO}_{4}\right]$} & 0.0208 & 0.0511 \\
{$\left[\mathrm{C}_{2} \mathrm{mim}\right]\left[\mathrm{Tf}_{2} \mathrm{~N}\right]$} & 0.0010 & 0.3775 \\
{$\left[\mathrm{C}_{6} \mathrm{mim}\right]\left[\mathrm{Tf}_{2} \mathrm{~N}\right]$} & 0.0016 & 0.5324 \\
\hline
\end{tabular}

To understand the cause of the disagreement, in Figure 7 we plot $\ln \alpha\left(T, x_{1}^{0} \rightarrow 1, x_{3}\right)$ and $\ln \alpha\left(T, x_{1}^{0} \rightarrow 0, x_{3}\right)$ versus $x_{3}$ for $\left[\mathrm{C}_{2} \mathrm{mim}\right]\left[\mathrm{Tf}_{2} \mathrm{~N}\right],\left[\mathrm{C}_{6} \mathrm{mim}\right]\left[\mathrm{Tf}_{2} \mathrm{~N}\right]$ and $\left[\mathrm{C}_{4} \mathrm{C}_{1} \mathrm{pyr}\right]\left[\mathrm{Tf}_{2} \mathrm{~N}\right]$. We find that for $\left[\mathrm{C}_{2} \mathrm{mim}\right]\left[\mathrm{Tf}_{2} \mathrm{~N}\right]$ and $\left[\mathrm{C}_{6} \operatorname{mim}\right]\left[\mathrm{Tf}_{2} \mathrm{~N}\right], \ln \alpha\left(T, x_{1}^{0} \rightarrow 1, x_{3}\right)$ crosses the $\ln \alpha=0$ reference line twice. Considering only these limiting conditions, this would suggest that we break the azeotrope for very small $x_{3}$ with $\alpha>0$, then form a maximum boiling azeotrope at higher concentrations, and then again break the azeotrope with $\alpha<0$.

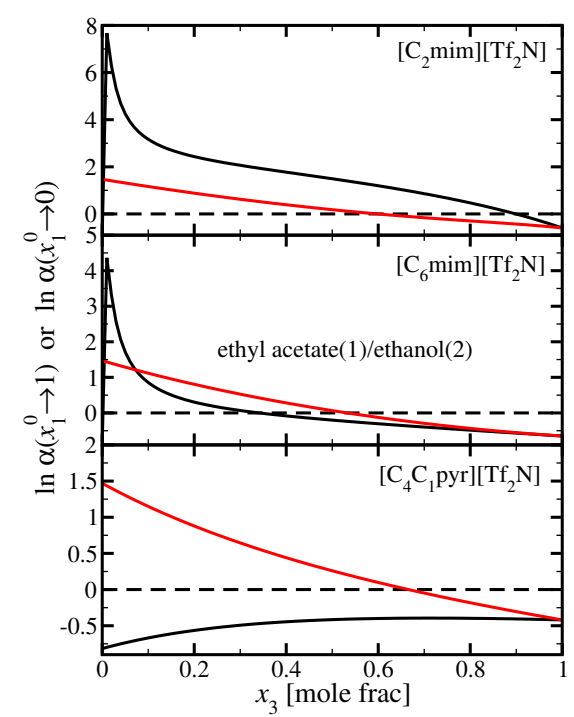

Figure 7. Plot of the limiting relative volatility ( $\alpha$ when $x_{1}^{0} \rightarrow 0$ and $x_{1}^{0} \rightarrow 1$ ) as a function of IL mole frac $\left(x_{3}\right)$ for the binary system ethyl acetate(1)/ethanol(2) at $313.15 \mathrm{~K}$. The horizontal dashed line corresponds to $\ln \alpha=0(\alpha=1)$ and is drawn as a reference, and the IL is indicated in the figure panes.

In Figure 8, we plot $\ln \alpha\left(T, x_{1}^{0}, x_{3}\right)$ versus $x_{1}^{0}$ for fixed values of $x_{3}$ with $\left[\mathrm{C}_{2} \operatorname{mim}\right]\left[\mathrm{Tf}_{2} \mathrm{~N}\right]$ and $\left[\mathrm{C}_{4} \mathrm{C}_{1}\right.$ pyr $]\left[\mathrm{Tf}_{2} \mathrm{~N}\right]$. The behavior with $\left[\mathrm{C}_{2} \mathrm{mim}\right]\left[\mathrm{Tf}_{2} \mathrm{~N}\right]$ is most interesting. With the addition of a very small mole frac of IL, we form a poly-azeotropic system. Considering $\alpha$ with $x_{3}=0.02, \alpha$ is twice equal to 1 , forming a minimum and maximum boiling azeotrope. Only at higher values of $x_{3}$ is the azeotrope broken. We find similar behavior for $\left[\mathrm{C}_{6} \mathrm{mim}\right]\left[\mathrm{Tf}_{2} \mathrm{~N}\right]$. This is not the case with $\left[\mathrm{C}_{4} \mathrm{C}_{1}\right.$ pyr] $\left[\mathrm{Tf}{ }_{2} \mathrm{~N}\right]$, demonstrating the unique phase behavior that may be obtained with changes to the cation and anion. 


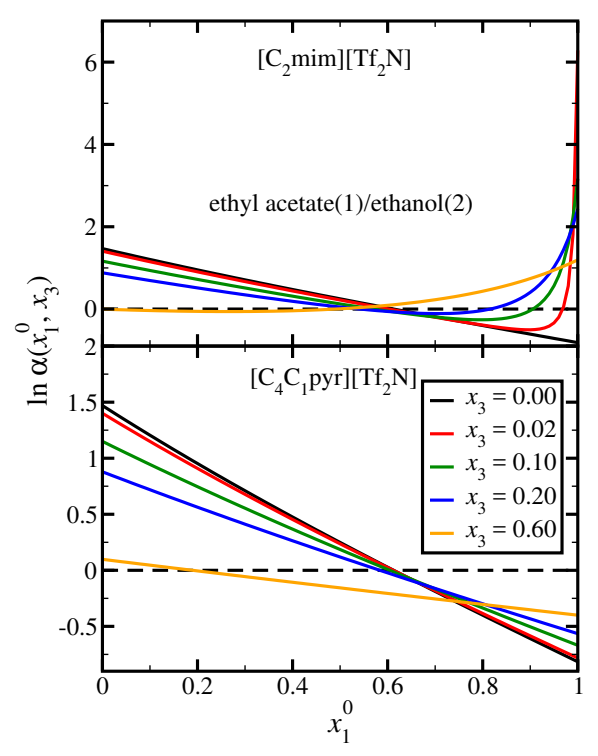

Figure 8. Plot of the relative volatility $(\alpha)$ as a function of the IL free mole frac of methanol $\left(x_{1}^{0}\right)$ for the binary system ethyl acetate(1)/ethanol(2) at $313.15 \mathrm{~K}$. The lines correspond to different, fixed values of $x_{3}$, as indicated in the legend. The horizontal dashed line corresponds to $\ln \alpha=0(\alpha=1)$, and is drawn as a reference. The top pane corresponds to use of the IL $\left[\mathrm{C}_{2} \mathrm{mim}\right]\left[\mathrm{Tf}_{2} \mathrm{~N}\right]$ and the bottom pane corresponds to $\left[\mathrm{C}_{4} \mathrm{C}_{1}\right.$ pyr $]\left[\mathrm{Tf}_{2} \mathrm{~N}\right]$.

In Figure 9, we plot $\ln \alpha\left(T, x_{1}^{0} \rightarrow 1, x_{3}\right)$ and $\ln \alpha\left(T, x_{1}^{0} \rightarrow 0, x_{3}\right)$ versus $x_{3}$ for $\left[\mathrm{C}_{2} \mathrm{mim}\right]\left[\mathrm{MeSO}_{3}\right]$, $\left[\mathrm{C}_{2} \mathrm{mim}\right]\left[\mathrm{MeSO}_{4}\right]$, and $\left[\mathrm{C}_{4} \mathrm{mim}\right]\left[\mathrm{CF}_{3} \mathrm{SO}_{3}\right]$. Here, we point out the case of $\left[\mathrm{C}_{4} \mathrm{mim}\right]\left[\mathrm{CF}_{3} \mathrm{SO}_{3}\right]$, which is similar to the use of $\left[\mathrm{C}_{4} \mathrm{mim}\right][\mathrm{Cl}]$ for ethanol(1)/water(2). At approximately $x_{3}=0.96$, we form a maximum boiling azeotrope, which is then broken at approximately $x_{3}=0.98$ after which $\alpha<1$. Again, we find that the values in the limit that $x_{3} \rightarrow 1$ does not capture the complete phase behavior of the system.

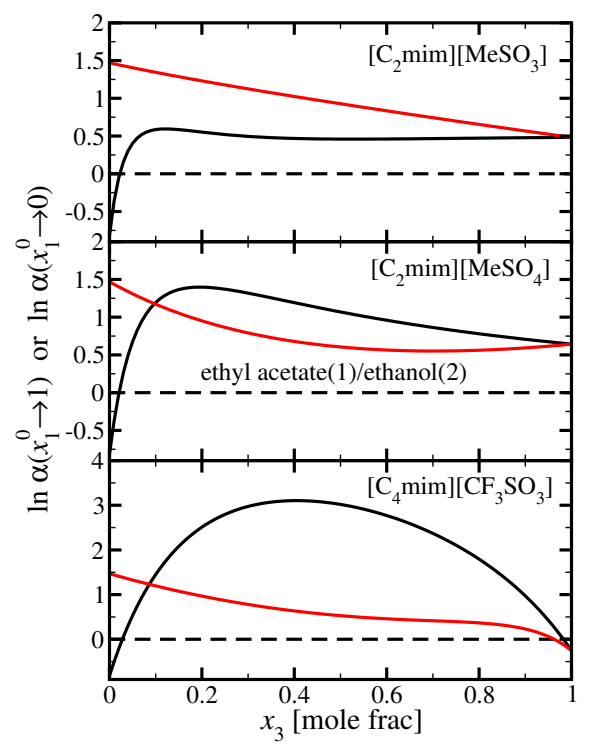

Figure 9. Plot of the limiting relative volatility ( $\alpha$ when $x_{1}^{0} \rightarrow 0$ and $x_{1}^{0} \rightarrow 1$ ) as a function of IL mole frac $\left(x_{3}\right)$ for the binary system ethyl acetate(1)/ethanol(2) at $313.15 \mathrm{~K}$. The horizontal dashed line corresponds to $\ln \alpha=0(\alpha=1)$ and is drawn as a reference, and the IL is indicated in the figure panes. 


\section{Summary and Conclusions}

Room temperature ionic liquids are ideal candidates for use as entrainers (or solvents) in extractive distillation processes. Their tuneability allows one to design ionic liquids selective in their interaction for one component over the other. Cases have been shown wherein only a minute amount of ionic liquid is needed to break an azeotrope, outperforming conventional entrainers. Additionally, their negligibly vapor pressure (volatility) facilitates recovery and minimizes loses. Here, we proposed an extension of the method of Brandani [29] to ternary systems to identify the ability of an ionic liquid entrainer to break an azeotrope. We demonstrated that we obtain the limiting selectivity $\left(S^{\infty}\right)$ as a limiting condition. The limiting selectivity is commonly used to screen and rank entrainer candidates, and is calculated as the ratio of the limiting activity coefficient of the most volatile component relative to the least volatile component in the pure ionic liquid. We find that, while for many cases the limiting selectivity can be used to rank ionic liquid candidates, its use is not always appropriate.

We, instead, recommend the use of composition dependent activity coefficients. This does not necessarily complicate the analysis of the use of an ionic liquid as an entrainer. Consider the NRTL equation used here. If we were to fix the value of the non-randomness parameter $(\alpha)$, then limiting activity coefficients of the constituent binary pairs can be used to obtain the necessary model parameters.

Author Contributions: Conceptualization, A.S.P. and P.D.; Data curation, A.S.P. and P.D.; Formal analysis, A.S.P.; Funding acquisition, A.S.P.; Methodology, A.S.P.; Project administration, A.S.P.; Software, A.S.P.; Supervision, A.S.P.; Validation, A.S.P.; Visualization, A.S.P.; Writing—original draft, A.S.P.; Writing—review \& editing, A.S.P. and P.D.

Funding: Acknowledgment is made to the donors of the American Chemical Society Petroleum Research Fund (56896-UNI6) for support of this research.

Conflicts of Interest: The authors declare no conflict of interest. The funders had no role in the design of the study; in the collection, analyses, or interpretation of data; in the writing of the manuscript, or in the decision to publish the results.

\section{References}

1. Wankat, P.C. Separation Process Engineering: Includes Mass Transfer, 3rd ed.; Pearson Education, Inc.: Upper Saddle River, NJ, USA, 2012.

2. Kumar, R.; Prausnitz, J.M.; King, C.J., Process Design Considerations for Extractive Distillation: Separation of Propylene-Propane. In Extractive and Azeotropic Distillation; American Chemical Society: Washington, DC, USA, 1972; Chapter 2, pp. 16-34.

3. Tassios, D.P. Rapid Screening of Extractive Distillation Solvents. In Extractive and Azeotropic Distillation; American Chemical Society: Washington, DC, USA, 1972; Chapter 4, pp. 46-63.

4. Basios, J.C.; Soares, M.E.; Medina, A.G. Selection of Solvents for Extractive Distillation. A Data Bank for Activity Coefficients at large Dilution. Ind. Eng. Chem. Process Des. Dev. 1985, 24, 420-426.

5. Zhu, Z.; Geng, X.; He, W.; Chen, C.; Wang, Y.; Gao, J. Computer-Aided Screening of Ionic Liquids As Entrainers for Separating Methyl Acetate and Methanol via Extractive Distillation. Ind. Eng. Chem. Res. 2018, 57, 9656-9664. [CrossRef]

6. Paduszyński, K. In Silico Calculation of large Dilution Activity Coefficients of Molecular Solutes in Ionic Liquids: Critical Review of Current Methods and New Models Based on Three Machine Learning Algorithms. J. Chem. Inf. Model 2016, 56, 1420-1437. [CrossRef] [PubMed]

7. Lazzaroni, M.J.; Bush, D.; Eckert, C.A.; Frank, T.C.; Gupta, S.; Olson, J.D. Revision of MOSCED Parameters and Extension to Solid Solubility Calculations. Ind. Eng. Chem. Res. 2005, 44, 4075-4083. [CrossRef]

8. Angell, C.A.; Ansari, Y.; Zhao, Z. Ionic Liquids: Past, present, and future. Faraday Discuss. 2012, 154, 9-27. [CrossRef] [PubMed]

9. Brennecke, J.F.; Maginn, E.J. Ionic Liquids: Innovative Fluids for Chemical Processing. AIChE J. 2001, 47, 2384-2389. [CrossRef] 
10. Dhanalakshmi, J.; Sai, P.S.T.; Balakrishnan, A.R. Study of Ionic Liquids as Entrainers for the Separation of Methyl Acetate-Methanol and Ethyl Acetate-Ethanol Systems Using the COSMO-RS Model. Ind. Eng. Chem. Res. 2013, 52, 16396-16405. [CrossRef]

11. Ge, Y.; Zhang, L.; Yuan, X.; Geng, W.; Ji, J. Selection of ionic liquids as entrainers for separation of (water + ethanol). J. Chem. Thermodyn. 2008, 40, 1248-1252. [CrossRef]

12. Cao, L.; Liu, P.; Wang, B.; Li, Q. Vapor-liquid equilibria for tetrahydrofuran + ethanol system containing three different ionic liquids at $101.3 \mathrm{kPa}$. Fluid Phase Equilib. 2014, 372, 49-55. [CrossRef]

13. Zhang, Z.; Hu, A.; Zhang, T.; Zhang, Q.; Sun, M.; Sun, D.; Li, W. Separation of methyl acetate + methanol azeotropic mixture using ionic liquids as entrainers. Fluid Phase Equilib. 2015, 401, 1-8. [CrossRef]

14. Dohnal, V.; Baránková, E.; Blahut, A. Separation of methyl acetate + methanol azeotropic mixture using ionic liquids as entrainers. Chem. Eng. J. 2014, 237, 199-208. [CrossRef]

15. Chai, J.; Cui, X.; Zhang, Y.; Li, R.; Feng, T. Vapor-Liquid Equilibrium and Liquid-Liquid Equilibrium of Methyl Acetate + Methanol + 1-Ethyl-3-methylimidazolium Acetate. J. Chem. Eng. Data 2011, 56, 282-287.

16. Chai, J.; Cui, X.; Zhang, Y.; Li, R.; Feng, T. Isobaric Vapor-Liquid Equilibrium for Methanol + Methyl Acetate + 1-Octyl-3-methylimidazolium Hexafluorophosphate at $101.3 \mathrm{kPa}$. J. Chem. Eng. Data 2011, 56, 2884-2888.

17. Andreatta, A.E.; Charnley, M.P.; Brennecke, J.F. Using Ionic Liquids to Break the Ethanol-Ethyl Acetate Azeotrope. ACS Sustain. Chem. Eng. 2015, 3, 3435-3444. [CrossRef]

18. Lei, Z.; Dai, C.; Zhu, J.; Chen, B. Extractive Distillation with Ionic Liquids: A Review. AIChE J. 2014, 60, 3312-3329. [CrossRef]

19. Jongmans, M.T.G.; Schuur, B.; de Haan, A.B. Ionic Liquid Screening for Ethylbenzene/Styrene Separation by Extractive Distillation. Ind. Eng. Chem. Res. 2011, 50, 10800-10810. [CrossRef]

20. Song, Z.; Zhou, T.; Qi, Z.; Sundmacher, K. Systematic Method for Screening Ionic Liquids as Extraction Solvents Exemplified by an Extractive Desulfurization Process. ACS Sustain. Chem. Eng. 2017, 5, 3382-3389. [CrossRef]

21. Navarro, P.; Larriba, M.; Delgado-Mellado, N.; Ayuso, M.; Romero, M.; García, J.; Rodríguez, F. Experimental screening towards developing ionic liquid-based extractive distillation in the dearomatization of refinery streams. Sep. Purif. Technol. 2018, 201, 268-275. [CrossRef]

22. Zhu, Z.; Ri, Y.; Li, M.; Jia, H.; Wang, Y.; Wang, Y. Extractive distillation for ethanol dehydration using imidazolium-based ionic liquids as solvents. Chem. Eng. Process. Process Intensif. 2016, 109, 190-198. [CrossRef]

23. Kulajanpeng, K.; Suriyapraphadilok, U.; Gani, R. Systematic screening methodology and energy efficient design of ionic liquid-based separation processes. J. Clean. Prod. 2016, 11, 93-107. [CrossRef]

24. Ley, R.T.; Paluch, A.S. Understanding the large solubility of lidocaine in 1-n-butyl-3-methylimidazolium based ionic liquids using molecular simulation. J. Chem. Phys. 2016, 144, 084501. [CrossRef] [PubMed]

25. Caudle, M.R.; Cox, C.E.; Ley, R.T.; Paluch, A.S. A molecular study of the wastewater contaminants atenolol and atrazine in 1-n-butyl-3-methylimidazolium based ionic liquids for potential treatment applications. Mol. Phys. 2017, 115, 1264-1273. [CrossRef]

26. Paluch, A.S.; Lourenço, T.C.; Han, F.; Costa, L.T. Understanding the Solubility of Acetaminophen in 1-n-Alkyl-3-methylimidazolium-Based Ionic Liquids Using Molecular Simulation. J. Phys. Chem. B 2016, 120, 3360-3369. [CrossRef] [PubMed]

27. Granberg, R.A.; Rasmuson, A.C. Solubility of Paracetamol in Binary and Ternary Mixtures of Water + Acetone + Toluene. J. Chem. Eng. Data 2000, 45, 478-483. [CrossRef]

28. Prausnitz, J.M.; Lichtenthaler, R.N.; de Azevedo, E.G. Molecular Thermodynamics of Fluid-Phase Equilibria, 2nd ed.; Prentice-Hall, Inc.: Englewood Cliffs, NJ, USA, 1986.

29. Brandani, V. Use of large-Dilution Activity Coefficients for Predicting Azeotrope Formation at Constant Temperature and Partial Miscibility in Binary Liquid Mixtures. Ind. Eng. Chem. Fundam. 1974, 13, 154-156. [CrossRef]

30. Larson, R.E.; Hostetler, R.P.; Edwards, B.H. Calculus, 6th ed.; Houghton Mifflin Company: New York, NY, USA, 1998.

31. Tsirlin, A.; Sukin, I.A.; Balunov, A.; Schwalbe, K. The Rule of Temperature Coefficients for Selection of Optimal Separation Sequence for Multicomponent Mixtures in Thermal Systems. J. Non-Equilib. Thermodyn. 2017, 42, 359-369. [CrossRef]

32. Momoh, S.O. Assessing the Accuracy of Selectivity as a Basis for Solvent Screening in Extractive Distillation Processes. Sep. Sci. Technol. 1991, 26, 729-742. [CrossRef] 
33. Kister, H.Z. Distillation Design; McGraw Hill, Inc.: New York, NY, USA, 1992.

34. Shulgin, I.; Fischer, K.; Gmehling, J. Classification of Homogeneous Binary Azeotropes. Ind. Eng. Chem. Res. 2001, 40, 2742-2747. [CrossRef]

35. Missen, R.W. On Criteria for Occurence of Azeotropes in Isothermal and Isobaric Binary Systems. Can. J. Chem. Eng. 2005, 83, 667-674. [CrossRef]

36. Missen, R.W. On Determination of Azeotropic Coordinates from $\mathrm{g}^{E}$ for Binary Isothermal and Isobaric Systems. Can. J. Chem. Eng. 2006, 84, 316-321. [CrossRef]

37. Earle, M.J.; Esperança, J.M.S.S.; Gilea, M.A.; Canongia Lopes, J.N.; Rebelo, L.P.N.; Magee, J.W.; Seddon, K.R.; Widegren, J.A. The distillation and volatility of ionic liquids. Nature 2006, 439, 831-834. [CrossRef] [PubMed]

38. Rai, N.; Maginn, E.J. Vapor-Liquid Coexistence and Critical Behavior of Ionic Liquids via Molecular Simulation. J. Phys. Chem. Lett. 2011, 2, 1439-1443. [CrossRef]

39. Rai, N.; Maginn, E.J. Critical behaviour and vapour-liquid coexistence of 1-alkyl-3-methylimidazolium bis(trifluoromethylsulfonyl)amide ionic liquids via Monte Carlo simulations. Faraday Discuss. 2012, 154, 53-69. [CrossRef] [PubMed]

40. Rane, K.S.; Errington, J.R. Saturation Properties of 1-Alkyl-3-methylimidazolium Based Ionic Liquids. J. Phys. Chem. B 2014, 118, 8734-8743. [CrossRef] [PubMed]

41. Yaws, C.L.; Narasimhan, P.K.; Gabbula, C. Yaws' Handbook of Antoine Coefficients for Vapor Pressure (2nd Electronic Edition); Knovel: New York, NY, USA, 2009.

(C) 2018 by the authors. Licensee MDPI, Basel, Switzerland. This article is an open access article distributed under the terms and conditions of the Creative Commons Attribution (CC BY) license (http:/ / creativecommons.org/licenses/by/4.0/). 